\title{
Evaluation of female factors in infertility by diagnostic laparohysteroscopy in a tertiary health care centre
}

\author{
Kashish Garg, Dhruba Prasad Paul*, Jayanta Ray
}

Department of Obstetrics and Gynecology, AGMC and GBP Hospital Agartala, Tripura, India

Received: 07 July 2020

Revised: 25 July 2020

Accepted: 29 July 2020

\section{*Correspondence:}

Dr. Dhruba Prasad Paul,

E-mail: dhrubaprasadpaul@gmail.com

Copyright: (c) the author(s), publisher and licensee Medip Academy. This is an open-access article distributed under the terms of the Creative Commons Attribution Non-Commercial License, which permits unrestricted non-commercial use, distribution, and reproduction in any medium, provided the original work is properly cited.

\begin{abstract}
Background: The inability to conceive is one of the most distressing conditions for a couple. It not only makes the female incomplete but also the social taboos attached are phenomenal. The problem of infertility as long as the recorded history of mankind. Fertility in our culture stands for reproductivity, growth and continuity. Reproduction is one of the basic essential for the survival of a species. Diagnostic laparoscopy \& hysteroscopy have emerged as an accurate method of assessing, evaluating and treating infertility. Direct visualization of the abdominal and pelvic organs in laparohysteroscopy allows a definitive diagnosis to be made in many conditions where clinical examination and less invasive techniques such as ultrasound and hysterosalpingography fail to identify the problem.

Methods: A prospective study was conducted in Department of Obstetrics and Gynaecology, AGMC\& GBP Hospital Agartala. 50 infertile women suspected with pelvic (tubal, peritoneal, adnexal) and intrauterine (uterine polyp, septa, submucous fibroid, intrauterine adhesions) pathologies were included in the study for further evaluation and correlation of clinical findings with Laparohysteroscopy observations.

Results: Out of 50 cases, $27(54 \%)$ patients had primary infertility. While laparoscopy detected abnormalities in $60 \%$ of the cases, significant hysteroscopy findings were noted in $66 \%$ of cases. The most common laparoscopic abnormality was tubal (22\%) ovarian and peritoneal (16\%) in primary and secondary infertile patients respectively. On hysteroscopy, endometrial polyp (30\%) was found as the commonest abnormality in both the groups.

Conclusions: Laparoscopy and hysteroscopy are both diagnostic and therapeutic procedures. If pathology is discovered, it can often be treated simultaneously. Laparoscopy combined with hysteroscopy is the sole technique to have a direct view of the female reproductive tract and to find out the various causes of infertility.
\end{abstract}

Keywords: Hysteroscopy, Infertility, Laparoscopy

\section{INTRODUCTION}

The inability to conceive is one of the most distressing conditions for a couple. It is not only making the female incomplete but also the social taboos attached are phenomenal.

Reproduction is a basic essential for survival of species. A modern-day Society has placed a high pressure on family and woman has been encouraged to assume the biologic role of giving birth and nurturing children.
The inability to procreate is frequently considered a personal tragedy and a curse for the couple, impacting on the entire family and even the local community. Negative psychosocial consequences of childlessness are common and often severe. ${ }^{1}$ One of the most important and underappreciated reproductive health problems in developing countries is the high rate of infertility. Although good documentation of the prevalence of infertility is lacking, it is generally believed that more than 70 million couples suffer from infertility worldwide. $^{2}$ Infertility affects about $10-15 \%$ of 
reproductive age couples. ${ }^{3}$ WHO estimated that the prevalence of infertility ranges from $3.9 \%$ to $16.8 \%$ in India. ${ }^{4}$ Incidence of female infertility is $45.67 \%$, male infertility is $54.33 \%$ and may be both can get involved in some of cases, range varies from region to region. ${ }^{5}$

The current evidence indicates $9 \%$ prevalence of infertility (of 12 months) with $56 \%$ couples seeking medical care in more developed and $51.2 \%$ in less developed countries. ${ }^{6}$ Female factors of infertility were more common $(57.5 \%)$ in central part of India. ${ }^{7}$ In all the districts of Tripura, the infertility problem including primary and secondary infertility among ever married women ranges from $5.3 \%$ to $7.3 \%{ }^{8}$

WHO (World Health Organization) defines infertility as "a disease of the reproductive system defined by the failure to achieve a clinical pregnancy after 12 months or more of regular unprotected sexual intercourse. ${ }^{9}$ Infertility may be primary or secondary. Primary infertility there is no prior pregnancy. Secondary infertility-infertility following at least one prior conception, although not necessarily a live birth. ${ }^{10}$

Today in the era of scientific advancement and technology, newer diagnostic modalities have paved the path for further insight in to this problem.

Laparohysteroscopy has emerged in recent years as an accurate method of assessing, evaluating and treating infertility. It is the third eye if the gynaecologists and hence a must in every theatre of today's world.

Direct visualization of the abdominal and pelvic organs inside out in laparohysteroscopy allows a definitive diagnosis to be made in many conditions where clinical examinations and less invasive techniques such as ultrasound and HSG fails to identify the problem like pelvic adhesions \& endometriosis. It is also helpful in diagnosis uterine, peritoneal and ovarian factors. Hence diagnostic laparohysteroscopy remains an essential part of the complete assessment of the infertile couple.

With this backdrop, this study was carried out to determine the different causes of female infertility, and their comparative frequency in patients with primary and secondary infertility on diagnostic laparohysteroscopy at the study centre.

The aim of this study was evaluation of female factors in infertility by diagnostic laparohysteroscopy in a tertiary health care centre.

An objective of the study was to find out the proportions of infertile females having tubal block, endometriosis, pelvic adhesions, ovarian cysts, fibroid, etc by laparoscopy and to find out the proportions of infertile females having uterine septum, intrauterine adhesions, uterine polyp or sub mucous fibroid etc by hysteroscopy.

\section{METHODS}

This was a prospective study of 50 patients with history of primary or secondary infertility selected from OPD of AGMC \& GBP hospital Agartala for a period of 1 and half years (Jan 2018 to June 2019).

\section{Inclusion criteria}

All infertile women suspected with pelvic (tubal, peritoneal, adnexal) and intrauterine (uterine polyp, septa, submucous fibroid, intrauterine adhesions) pathology were included in the study for further evaluation and correlation of clinical findings with laparohysteroscopy observations

\section{Exclusion criteria}

Those who may deny participation in the study; medical disorders which are contraindication for general anaesthesia and laparohysteroscopy; male factor infertility were excluded from this study.

All registered women who fulfilled the inclusion criteria were first counselled regarding aim of the study and procedures of the study. Written consent was taken from them in the language they understood.

All patients within the inclusion criteria subjected to detailed history pertaining to Infertility, obstetric carrier, menstrual cycle past, personal and family history along with any treatment history for both male and female.

The female partner was subjected to clinical examination right from head to toe examination as well as systemic examination along with local and gynaecological examination. Underwent certain basic blood investigations, ultrasonography (USG) pelvis and husband's semen analysis; and patient was asked to follow-up with next menstrual cycle. Patients selected for laparoscopic, hysteroscopic evaluation were admitted in the pre-ovulatory phase.

Diagnostic Laparohysteroscopy was performed in all 50 cases. First hysteroscopy was performed followed by diagnostic laparoscopy in the same setting. Diagnostic hysteroscope was performed in gynaecology operation theatre under spinal anaesthesia using $4 \mathrm{~mm}$ telescope and normal saline as distending media. Uterine cavity, tubal ostia and endometrium were looked for any pathology Simultaneous diagnostic laparoscopy \& chromopertubation had done to check the patency of tubes by injecting dilute methylene blue through the intrauterine cannula and look for any extrauterine, tubal, ovarian, peritoneal pathology. All the data was recorded on a predesigned format. After the procedure, patient was transferred to postoperative ward and was discharged next day.

The collected data was compiled and proper statistical formulas. Data entry and analysis was done using SPSS 
version 20.0 statistical software. Data was expressed in frequency and percentage in form of tables and charts.

\section{RESULTS}

A cross sectional clinical study consisting of 50 infertile patients both primary and secondary is undertaken to know the role of diagnostic laparohysteroscopy in the evaluation of infertility.

In present study out of 50 cases (Table 1) 27 (54\%) were primary infertility and $23(46 \%)$ were of secondary infertility.

Table 1: Distribution of cases according to type of infertility.

\begin{tabular}{|lll|}
\hline Type of infertility & No & $\%$ \\
\hline Primary & 27 & 54 \\
\hline Secondary & 23 & 46 \\
\hline Total & 50 & 100 \\
\hline
\end{tabular}

Table 2: Age distribution of primary and secondary infertility.

\begin{tabular}{|c|c|c|c|c|}
\hline \multirow[t]{2}{*}{$\begin{array}{l}\text { Age in } \\
\text { years }\end{array}$} & \multicolumn{2}{|c|}{ Primary (27) } & \multirow{2}{*}{$\begin{array}{l}\text { SECON } \\
\text { No }\end{array}$} & \multirow{2}{*}{$\begin{array}{l}\text { DARY (23) } \\
\%\end{array}$} \\
\hline & No & $\%$ & & \\
\hline $15-20$ & 1 & 4 & 3 & 13 \\
\hline $21-25$ & 7 & 26 & 1 & 4 \\
\hline $26-30$ & 8 & 29 & 6 & 26 \\
\hline $31-35$ & 7 & 26 & 8 & 35 \\
\hline $36-40$ & 4 & 15 & 4 & 18 \\
\hline $41-45$ & 0 & 0 & 1 & 4 \\
\hline Total & 27 & 100 & 23 & 100 \\
\hline
\end{tabular}

Table 3: Duration of infertility.

\begin{tabular}{|lllll|}
\hline $\begin{array}{l}\text { Duration of } \\
\text { infertility in years }\end{array}$ & \multicolumn{2}{c|}{ Primary (27) } & \multicolumn{2}{c|}{ Secondary (23) } \\
\hline & No & \% & No & \% \\
\hline$<2$ & 3 & 11 & 0 & 0 \\
\hline $\mathbf{2 - 5}$ & 12 & 44 & 10 & 43 \\
\hline $\mathbf{6 - 1 0}$ & 10 & 37 & 12 & 52 \\
\hline$>\mathbf{1 0}$ & 2 & 8 & 1 & 5 \\
\hline Total & 27 & 100 & 23 & 100 \\
\hline
\end{tabular}

In primary infertility cases, maximum number of patient (29\%) belonged to age group of 26-30 years whereas maximum number of secondary infertility cases $(35 \%)$ were under the age group of 31-35 years as given in (Table 2).

Most of the patients among primary infertility (44\%) were having infertility duration ranging from 2-5 years, as against secondary infertility $(52 \%)$ who were infertile for 6-10 years as shown in (Table 3).
In the present study, majority of the cases of secondary infertility -18 had previous history abortion $(78 \%)$. out of 18 cases 14 had induced and 4 had spontaneous, out of 14 induced 6 had history of check curettage.

Congenital anomalies as Mullerian anomalies were found in 1 case $(3.7 \%)$ of primary infertility had uterine didelphius, $3.7 \%$ patients had fibroid uterus in primary infertility and 0 in secondary infertility (Table 4$)$. In our study uterine factors accounted for $6 \%$ infertility cases.

Table 4: Causes of infertility through diagnostic laparoscopy.

\begin{tabular}{|c|c|c|c|c|c|c|}
\hline \multirow[t]{2}{*}{$\begin{array}{l}\text { Causes of } \\
\text { infertility }\end{array}$} & \multicolumn{2}{|c|}{$\begin{array}{l}\text { Primary } \\
(27)\end{array}$} & \multicolumn{2}{|c|}{$\begin{array}{l}\text { Secondary } \\
(23)\end{array}$} & \multicolumn{2}{|c|}{$\begin{array}{l}\text { Total } \\
\text { (50) }\end{array}$} \\
\hline & No & $\%$ & No & $\%$ & No & $\%$ \\
\hline $\begin{array}{l}\text { Uterine } \\
\text { factors }\end{array}$ & 3 & 11.1 & - & - & 3 & 6 \\
\hline $\begin{array}{l}\text { Tubal } \\
\text { blockage } \\
\text { (unilateral ) }\end{array}$ & 2 & 7.4 & 4 & 17 & 6 & 12 \\
\hline $\begin{array}{l}\text { Tubal } \\
\text { blockage } \\
\text { (bilateral) }\end{array}$ & 3 & 11 & 2 & 8.6 & 5 & 10 \\
\hline Ovarian cyst & 7 & 25.9 & 1 & 4.3 & 8 & 16 \\
\hline $\begin{array}{l}\text { Pelvic } \\
\text { adhesions }\end{array}$ & 4 & 14.8 & 1 & 4.3 & 5 & 10 \\
\hline $\begin{array}{l}\text { Pelvic } \\
\text { endometriosis }\end{array}$ & 3 & 11.1 & 0 & 0 & 3 & 6 \\
\hline Unexplained & 5 & 18.5 & 15 & 65.2 & 20 & 40 \\
\hline Total & 27 & 100 & 23 & 100 & 50 & 100 \\
\hline
\end{tabular}

Table 5: Hysteroscopic findings of patients.

\begin{tabular}{|c|c|c|c|c|c|c|}
\hline \multirow[t]{2}{*}{$\begin{array}{l}\text { Causes of } \\
\text { infertility }\end{array}$} & \multicolumn{2}{|c|}{ Primary (27) } & \multicolumn{2}{|c|}{$\begin{array}{l}\text { Secondary } \\
\text { (23) }\end{array}$} & \multicolumn{2}{|c|}{ Total (50) } \\
\hline & No & $\%$ & No & $\%$ & No & $\%$ \\
\hline $\begin{array}{l}\text { Endometrial } \\
\text { polyp }\end{array}$ & 11 & 40 & 4 & 17.4 & 15 & 30 \\
\hline $\begin{array}{l}\text { Uterine } \\
\text { Septum }\end{array}$ & - & - & 2 & 8.7 & 2 & 4 \\
\hline $\begin{array}{l}\text { Intrauterine } \\
\text { adhesions }\end{array}$ & - & - & 8 & 34.8 & 8 & 16 \\
\hline $\begin{array}{l}\text { Submucous } \\
\text { fibroid }\end{array}$ & 1 & 3.7 & 4 & 17.4 & 5 & 10 \\
\hline $\begin{array}{l}\text { Obliterated } \\
\text { ostium }\end{array}$ & - & - & 3 & 13 & 3 & 6 \\
\hline Normal & 15 & 55.6 & 2 & 8.7 & 17 & 34 \\
\hline Total & 27 & 100 & 23 & 100 & 50 & 100 \\
\hline
\end{tabular}

In our study, tubal factors (Table 4) were responsible for (18.4) of primary and $(25.6 \%)$ of secondary infertility. Overall it accounted for $22 \%$ cases. Out of 11 cases 1 had B/L hydrosalpinx, 1 case had history of tuberculosis had distorted tube with pelvic congestion \& obliterated Pouch of doughlas.

Peritoneal factors (Table 4) were accounted for $25.9 \%$ of primary and $4.3 \%$ of secondary infertility cases. Pelvic 
endometriosis was only found in 3 cases of primary infertile patients. Isolated pelvic adhesions were seen in 4 cases of primary and 1 case of secondary infertile patients.

Majority of infertile patients had PCOD (Table 4) as ovarian factor. ovarian factors accounted for $16 \%$ of total cases of infertility $-25.9 \%$ in primary \& $4.3 \%$ secondary. The ovarian cyst which was simple ovarian cyst found in 2 cases of primary infertility and 1 case of secondary infertility.

In diagnostic laparoscopy (Table 4) majority of the infertile patients had tubal factors followed by ovarian and peritoneal. Among the cause in many cases, there were more than one factor. The most important and significant one was considered However, in spite of thorough laparoscopic evaluation no cause was revealed in $18.5 \%$ of primary \& $65.2 \%$ of secondary infertility ( $40 \%$ of total infertility) were included under unexplained infertility (Table 4).

On hysteroscopy (Table 5) 15 of the 27 patients in primary infertility group were found to have normal study. 11 patients (40\%) were diagnosed with endometrial polyps which were the commonest hysteroscopic finding in this group followed by submucous fibroid (3.7\%). Submucous fibroid was noted in 1 patient. An $82 \%$ patient with secondary infertility were found to have abnormal hysteroscopic picture. intrauterine adhesions were the leading cause (34.8\%) followed by endometrial polyp (17\%) cases \& submucous fibroid. 2 cases of intrauterine septum were noted and 3 case of obliterated ostium was noted. Intrauterine adhesions were $34.8 \%$ in the secondary infertility group compared to $0 \%$ in the primary infertility group.

Table 6: Complications of endoscopic procedure.

\begin{tabular}{|lll|}
\hline Complications & No & $\%$ \\
\hline Wound infection & - & - \\
\hline Abdominal pain & 4 & 8 \\
\hline Shoulder pain & 1 & 2 \\
\hline Nausea and vomiting & 4 & 8 \\
\hline Total & 9 & 18 \\
\hline
\end{tabular}

In our study no, major complications (Table 6) were noted. Few patients had mild to moderate discomfort in abdomen. However, severe abdominal pain noted in $2 \%$ cases. Overall the complication rate was $18 \%$.

\section{DISCUSSION}

Laparohysteroscopy plays a valuable role in diagnosis of infertility. It helps to detect various causes of infertility, which were unrevealed by other investigations.
Our study was conducted in 50 cases (Table 1) of infertile patients out of which $54 \%$ were suffering from primary infertility and $46 \%$ were of secondary infertility.

In our study comprising 50 patients (Table 4, 5) a total of $60 \%$ of patients had abnormal laparoscopic findings and $66 \%$ of patients had abnormal hysteroscopic picture.

Majority of primary infertility patients were in the age group (Table 2) of 26-30yrs (29\%) and that of secondary were in 31-35yrs (35\%) which was comparable to the study by Chaitra $\mathrm{K}$ et al this suggests that the patients are aware of their problems and are willing to undergo treatment for the same. ${ }^{11}$

In our study majority of patients in primary infertility group had duration (Table 3) of infertility 1-5yrs and secondary 6-10yrs. In the present study, majority of the cases of secondary infertility -18 had previous history abortion (78\%). Out of 18 cases 14 had induced and 4 had spontaneous .out of 14 induced 6 had history of check curettage.

Laparoscopy gives a magnified view of the pelvis, thereby resolving questions about tubal and ovarian morphology, tubal adhesions and also tubal patency. Endometriosis and peritoneal adhesions distort the tubo ovarian relationship and prevent the ovum pickup even though the tubes appear normal externally. Laparoscopy is the gold standard for diagnosis of these disorders and has the advantage of performing corrective surgery in the same sitting. In this study on laparoscopy (Table 4) Congenital anomalies as mullerian anomalies were found in 1 case $(3.7 \%)$ of primary infertility had uterine didelphius, $3.7 \%$ patients had fibroid uterus in primary infertility and 0 in secondary infertility. In our study uterine factors responsible for infertility in $11 \%$ in primary and $0 \%$ in secondary \& the results are comparable to Chaitra $\mathrm{K}$ et al ${ }^{(11)} 10 \%$ in primary and $6 \%$ in secondary, Rai A et al $11.5 \%$ in primary and $6 \%$ in secondary \& Mehta AV et al studies. ${ }^{12,13}$ In our study, tubal factors were responsible for (18.4) of primary and (23\%) of secondary infertility. Overall it accounted for $22 \%$ cases. Out of 11 cases 1 had B/L hydrosalpinx, 1 case had history of tuberculosis had distorted tube with pelvic congestion and obliterated pod. Tubal disease is an important cause of infertility and needs to be evaluated before starting fertility treatment. ${ }^{14}$ It indicates that tubal block still plays a major role in the aetiology of infertility and evaluation by laparoscopy along with chromopertubation will give a better idea regarding the cause and appropriate management of the condition also it can determine fimbrial function in addition to the patency of tubes.

Peritoneal factors were accounted for $25.9 \%$ of primary and $4.3 \%$ of secondary infertility cases. Pelvic endometriosis was only found in $17.1 \%$ of primary infertile patients. Studies suggested that $25 \%$ to $50 \%$ of infertile women have endometriosis and that $30 \%$ to $50 \%$ 
of women with endometriosis are infertile. ${ }^{15}$ Endometriosis may lead to female infertility, although it has not been confirmed whether endometriosis can be the sole cause of infertility or it is only contributory factor that leads to it. Nevertheless, most women who are infertile suffer from endometriosis. The clinical signs and symptoms that make one of endometriosis (dysmenorrhoea, dyspareunia, abnormal uterine bleeding, chronic pelvic pain and/or pelvic mass, utero-sacral ligament nodularity) are not reliable enough to justify diagnosis and treatment. Current thinking dictates visual and/or microscopic confirmation through laparoscope before diagnosing or treating a patient for endometriosis. ${ }^{16}$

Majority of infertile patients had PCOD as ovarian factor. ovarian factors accounted for $16 \%$ of total cases of infertility $-14.8 \%$ in primary \& $4.3 \%$ secondary. The ovarian cyst which was simple ovarian cyst found in 2 cases of primary infertility and 1 case of secondary infertility. The results are comparable to Chaitra $\mathrm{K}$ et al $20 \%$ in primary and $8 \%$ in secondary, Rai A et al $27 \%$ primary and $8 \%$ secondary \& Mehta AV et al $17 \%$ in primary and $5 \%$ secondary but however among findings of various other ovarian factors, in our study PCOS is more prevalent. ${ }^{11-13}$

In hysteroscopic evaluation (Table 5) endometrial polyp was seen in $40 \%$ cases of primary and $17.4 \%$ cases of secondary infertile patient .out of 23 secondary infertile patient $34.8 \%$ had intrauterine adhesions, $8.7 \%$ had uterine septum, submucous fibroid seen in $17 \%$ cases of secondary infertile patients. Diagnosis of endometrial polyps via hysteroscopy is 94\% sensitive and 92\% specific. For submucous myomas diagnostic hysteroscopy is $87 \%$ sensitive and $95 \%$ specific. ${ }^{17}$ Developmental uterine anomalies have long been associated with pregnancy loss and obstetric complications, but the data suggest that ability to conceive is generally not affected ,the pooled data suggest that the prevalence of septate uterus is similar in infertile and fertile women (approximately 1\%), but is significantly higher in women with recurrent pregnancy loss (approximately 3.5\%). ${ }^{18}$ Other than septate uterus, the major hysteroscopic abnormalities in our study were myomas and polyps. The evidence to suggest that uterine myomas decrease fertility is inferential and relatively weak; the bulk of it is derived from studies that had compared the prevalence of myomas in fertile and infertile women or the reproductive performance of women with otherwise unexplained infertility before and after myomectomy. ${ }^{19,20}$ Proposed mechanisms by which myomas might adversely affect fertility include cornual myomas that involve or compress the interstitial segment of the tube, dysfunctional uterine contractility interfering with sperm transport or embryo implantation, and poor regional blood flow resulting in focal endometrial attenuation or ulceration. The incidence of asymptomatic endometrial polyps in women with infertility has been reported to range from $10 \%$ to $32 \% .{ }^{21,22}$ In our study no, major complications were noted. Today the complication rate of endoscopic procedures has reduced significantly owing to better training, skills and anaesthetic techniques.

\section{CONCLUSION}

Laparoscopy and hysteroscopy are both diagnostic and therapeutic procedures. If pathology is discovered, it can often be treated simultaneously. Laparoscopy combined with hysteroscopy is the sole technique to have a direct view of the female reproductive tract and finding out the various causes of infertility.

Laparohysteroscopy is a quintessential tool for the diagnosis, treatment and prognosis as it allows the gynaecologists to develop the plan of therapy in infertile patients. Whenever the history, pelvic examination and diagnostic studies fail to elucidate a definite pathology laparoscopy should be considered as it gives a definitive direction to the gynaecologists regarding the treatment of anxious infertile women.

Laparohysteroscopy should be considered as complimentary to USG and HSG rather than competing with them in the evaluation of infertile patients.

Our study shows laparohysteroscopy great has great value in evaluation of infertile couples because of low complication rate, conclusive, easy to interpret findings. hence it is an indispensable diagnostic tool in the evaluation of infertile couples.

\section{ACKNOWLEDGMENTS}

Authors would like to thank our colleagues and hospital staff who provided expertise that greatly assisted the research.

\section{Funding: No funding sources Conflict of interest: None declared \\ Ethical approval: The study was approved by the Institutional Ethics Committee}

\section{REFERENCES}

1. Ombelet W, Cooke I, Dyer S, Serour G, Devroey P. Infertility and the provision of infertility medical services in developing countries. Human reproduction update. 2008;14(6):605-21.

2. Fathalla MF. Reproductive health: a global overview. Early Hum Dev. 1992;29:35-42.

3. Boivin J, Bunting L, Collins JA, Nygren KG. Reply: International estimates on infertility prevalence and treatment seeking: potential need and demand for medical care. Human reproduction. 2009;24(9):23803.

4. Chan SM, Rudra Pal GS, Panda S, Santa Singh AS. Diagnostic hysterolaparoscopy for evaluation of infertility: Our experience in a tertiary Care Hospital. J Hum Reprod Sci. 2018;11:19-23. 
5. Shamila S, Sasikala SL. Primary Report on the Risk Factors Affecting Female Infertility in South Indian Districts of Tamil Nadu and Kerala. Indian J Community Med. 2011;36(1):59-61.

6. Boivin J, Bunting L, Collins JA, Nygren KG. International estimates of infertility prevalence and treatment - seeking: potential need and demand for infertility medical care. Hum Reprod. 2007; 22:150612.

7. Aflatoonian A, Seyedhassani SM, Tabibnejad N. The epidemiological and etiological aspects of infertility in Yazd province of Iran. Iranian J Reprod Med. 2009;7:117-22.

8. International institute for population science. District level household \& facility survey: TRIPURA fact sheet. 2007-08. Available at: http://rchiips.org/pdf/dlhs3/report/TR.pdf. Accessed on 23 September, 2019.

9. Zegers-Hochschild F, Adamson GD, de Mouzon J, Ishihara $\mathrm{O}$, Mansour $\mathrm{R}$, Nygren $\mathrm{K}$, et al. The international committee for monitoring assisted reproductive technology (ICMART) and the world health organization (WHO) revised glossary on ART terminology, 2009. Fertil Steril. 2009;92(5):1520-4.

10. Aubuchon M, Burney RO, Schust DJ, Yao MW. Infertility and assisted Reproductive technology. Berek \& Novak's Gynecology. Fifteenth ed: Lippincott Williams \& Wilkins, a Wolters KLuwer business. 2012:1139.

11. Chaitra K, Prathima S, Chandraiah S, GS A. Laparoscopy as a diagnostic tool in evaluation of female factors in infertility. Int J Reprod Contracept Obstet Gynecol. 2017;6(3):864-7.

12. Rai A, Mishra MG. Diagnostic hystero-laparoscopy in work-up of female infertility. Inter $\mathbf{J}$ Reprod Contracep Obstet Gynecol. 2017;6(7):2853

13. Mehta AV, Modi AP, Raval BM, Munshi SP, Patel SB, Dedharotiya SM. Role of diagnostic hysterolaparoscopy in the evaluation of infertility. Int J Reprod Contracept Obstet Gynecol. 2016;5(2):4370 .
14. Practice Committee of the American Society for Reproductive Medicine. Diagnostic evaluation of the infertile female: a committee opinion. Fertility and sterility. 2015;103(6):e44-50.

15. Missmer SA, Hankinson SE, Spiegelman D, Barbieri RL, Marshall LM, Hunter DJ. Incidence of laparoscopically confirmed endometriosis by demographic, anthropometric, and lifestyle factors. American J Epidemiol. 2004;160(8):784-96.

16. Aziz N. Laparoscopic evaluation of female factors in infertility. J Coll Physicians Surg Pak. 2010;20(10):649-52.

17. Nayak P, Mahapatra P, Mallick J, Swain S, Mitra S, Sahoo J. Role of diagnostic hystero-laparoscopy in the evaluation of infertility: A retrospective study of 300 patients. J Hum Reprod Sci. 2013;6(1):32-4.

18. Homer HA, Li TC, Cooke ID. The septate uterus: A review of management and reproductive outcome. Fertil Steril. 2000;73:1-14.

19. Donnez J, Jadoul P. What are the implications of myomas on fertility? A need for a debate? Hum Reprod. 2002;17:1424-30.

20. Pritts EA. Fibroids and infertility: A systematic review of the evidence. Obstet Gynecol Surv. 2001;56:483-91.

21. Hinckley MD, Milki AA. 1000 office-based hysteroscopies prior to in vitro fertilization: Feasibility and findings. JSLS. 2004;8:103-7.

22. Shalev J, Meizner I, Bar-Hava I, Dicker D, Mashiach $\mathrm{R}$, Ben-Rafael Z. Predictive value of transvaginal sonography performed before routine diagnostic hysteroscopy for evaluation of infertility. Fertil Steril. 2000;73:412-7.

Cite this article as: Garg K, Paul DP, Ray J. Evaluation of female factors in infertility by diagnostic laparohysteroscopy in a tertiary health care centre. Int J Reprod Contracept Obstet Gynecol 2020;9:3596-601. 